\title{
ECONOMIA E AGRONEGÓCIO: A IMPORTÂNCIA DAS RELAÇÕES INTERNACIONAIS NO SETOR SUCROALCOOLEIRO
}

\author{
Ana Caroline Veiga
}

Universidade do Oeste Paulista, Curso de Administração, Presidente Prudente, SP. Email: veiga.caroline@hotmail.com

\begin{abstract}
RESUMO
A presente pesquisa relata a importância das práticas do agronegócio para o desenvolvimento da economia brasileira. No início, o setor de maior força era o setor cafeeiro e foi somente após a abertura da economia para o comércio exterior que começaram a surgir as grandes usinas no país. Com a economia do país em fase de crescimento, o apoio às exportações aumentava e o setor crescia gradativamente. Após estabilização econômica, as grandes usinas já estavam colaborando com grande parte das exportações brasileiras e com o passar dos anos, a quantidade de produtos fabricados e exportados, tornaram-se um diferencial na economia do país; um bom exemplo é a Usina Alto Alegre, que além de ser uma renomada empresa tem participação ativa no comércio exterior, mantendo relações com diversos países.
\end{abstract}

Palavras-chave: Agronegócio. Economia. Exportação. Açúcar.

\section{ECONOMY AND AGRIBUSINESS: THE IMPORTANCE OF INTERNATIONAL RELATIONS IN SUGARCANE SECTOR}

\begin{abstract}
This study reports the importance of agribusiness practices for the development of the Brazilian economy. At first the force majeure sector was the coffee sector and it was only after opening the economy to foreign trade that began to emerge the big plants in the country. With the economy in a growth phase, support for exports increased and the sector grew gradually. After economic stabilization, large plants were already working with most Brazilian exports and over the years the amount of products produced and exported, have become a differential in the economy; a good example is the Usina Alto Alegre, which besides being a renowned company is actively involved in foreign trade, maintaining relations with several countries .
\end{abstract}

Keywords: Agribusiness. Economy. Export. Sugar. 


\section{INTRODUÇÃO}

Antes do conceito e prática do agronegócio surgir, a agricultura era muito primitiva e com o decorrer dos anos, o comércio deixou de ser somente entre determinada região e passou a estender-se às outras propriedades que proporcionavam uma relação mais ampla entre os produtores. A região de Presidente Prudente, situada no Centro-Sul do país é reconhecida pela significativa parcela de contribuição para as relações internacionais do Brasil, uma vez que possui em suas dependências a sede de uma das principais usinas de açúcar e álcool do Brasil e do mundo, que mesmo diante da crise que vem atingindo o setor durante alguns anos, a região de Presidente Prudente vem se mantendo estável ao que se trata da produção de açúcar e álcool, fato que se deve à boa gestão das usinas da região. A pesquisa tem por principal objetivo identificar o crescimento do agronegócio e a maneira que está relacionado com o crescimento econômico, tendo como principal fonte de renda, o setor sucroalcooleiro.

\section{METODOLOGIA}

Os aspectos metodológicos deste projeto foi pesquisa descritiva, exploratória, estudo de caso e tem como instrumento de coleta de dados, a pesquisa bibliográfica com abordagem qualitativa.

Segundo Gil (2010, p. 27), "as pesquisas descritivas têm como objetivo a descrição das características de determinada população. Podem ser elaboradas também, com a finalidade de identificar possíveis relações entre variáveis", com o objetivo de descrever as ações do comércio exterior e do agronegócio comparando-o com o cenário macroeconômico atual.

Ainda neste estudo foi utilizado como meio de pesquisa, a exploratória, que segundo Andrade (2010, p. 112), pondera-se que:

A pesquisa exploratória é o primeiro passo de todo trabalho científico. São finalidade de uma pesquisa exploratória, sobretudo quando bibliográfica, proporcionar maiores informações sobre determinado assunto; facilitar a delimitação de um tema de trabalho; definir os objetivos ou formular as hipóteses de uma pesquisa ou descobrir novo tipo de enfoque para o trabalho que se tem em mente.

Desta forma, proporcionando maior familiaridade a respeito do tema, sendo possível maior entendimento e visa proporcionar uma visão geral dos fatos determinados.

Segundo Gil (2010, p. 37), “o estudo de caso consiste no estudo profundo e exaustivo de um ou poucos objetos, de maneira que permita seu amplo e detalhado conhecimento, tarefa praticamente impossível mediante outros delineamentos já considerados." Com isso, foi possível 
compreender os processos das empresas exportadoras e preservar os dados para que não haja distorção da realidade, possibilitando assim, a compreensão do tema desenvolvido.

Para complementar o estudo, também foi utilizado pesquisa documental, que de acordo com Marconi e Lakatos (2005, p. 176) "é que a fonte da coleta de dados está restrita a documentos, escritos ou não, constituindo o que se denomina de fontes primárias", sendo possível a análise através de documentos já existentes, sendo eles ocorridos na atualidade ou já há algum tempo.

“A pesquisa bibliográfica é elaborada com base em material já publicado. Tradicionalmente, esta modalidade de pesquisa inclui material impresso, como livros, revistas, jornais, teses, dissertações e anais de eventos científicos" (GIL 2010, p. 29), definindo-se através de uma ampla e detalhada pesquisa, fundamentada em diversos autores a fim de proporcionar maior conhecimento do tema. Além da pesquisa em livros, revistas e outros materiais já citados, foram utilizados também como apoio, materiais publicados em sites.

\section{RESULTADOS}

A Usina Alto Alegre é uma das principais do país quando se trata da produção e exportação de açúcar. Apresenta uma produção significativa em relação ao volume total brasileiro.

Conforme a busca de dados, foi possível constatar que durante os anos analisados da Usina Alto Alegre apresentou crescimento no total de produção, assim como no total destinado ao mercado externo.

Tabela 1. Análise de 2010

\begin{tabular}{|c|c|c|c|c|}
\hline PRODUTO & \multicolumn{2}{|r|}{ MERCADO } & PRODUÇÃO & VENDA \\
\hline \multirow{2}{*}{ Açúcar } & Interno & $\begin{array}{c}\text { São Paulo, Paraná, Santa Catarina e Rio } \\
\text { Grande do Sul }\end{array}$ & \multirow{2}{*}{848.095 ton } & 377.797 ton \\
\hline & Externo & Rússia, Índia, Angola, Gana e lêmen & & 384.393 ton \\
\hline \multirow{2}{*}{ Etanol } & Interno & A partir das distribuidoras & \multirow{2}{*}{$198.716 \mathrm{~m}^{3}$} & $205.413 \mathrm{~m}^{3}$ \\
\hline & Externo & A partir das distribuidoras & & - \\
\hline $\begin{array}{l}\text { Energia } \\
\text { Elétrica }\end{array}$ & Interno & A partir das concessionárias & 416.843 MWh & $233.005 \mathrm{MWh}$ \\
\hline
\end{tabular}

Fonte: A partir do Relatório de Sustentabilidade Alto Alegre 2010

Durante o exercício de 2010, a produção de açúcar correspondeu à aproximadamente $3,03 \%$ da produção nacional e a quantidade destinada ao mercado externo, $1,37 \%$ do total exportado. 
Tais valores, apesar de pequenos, indicam um importante percentual na economia do país e também para a Usina, pois além de proporcionar a liderança neste mercado, faz com que a mesma também ganhe credibilidade diante das diversas outras empresas neste ramo.

A Usina Alto Alegre mantém relações no comércio exterior também com os principais países importadores do açúcar brasileiro, sendo o maior consumo da Rússia e Índia, assim como a nível mundial.

Tabela 2. Análise de 2011

\begin{tabular}{|c|c|c|c|c|}
\hline Produto & & Mercado & Produção & Venda \\
\hline \multirow{2}{*}{ Açúcar } & Interno & $\begin{array}{l}\text { São Paulo, Paraná, Santa Cata- } \\
\text { rina e Rio Grande do Sul }\end{array}$ & \multirow{2}{*}{853.875 ton } & 362.679 ton \\
\hline & Externo & $\begin{array}{l}\text { Rússia, Índia, Angola, Gana e } \\
\text { lêmen }\end{array}$ & & 451.382 ton \\
\hline \multirow{2}{*}{ Etanol } & Interno & A partir das distribuidoras & \multirow{2}{*}{$202.861 \mathrm{~m} 3$} & $203.448 \mathrm{~m} 3$ \\
\hline & Externo & A partir das distribuidoras & & Não houve \\
\hline $\begin{array}{l}\text { Energia } \\
\text { elétrica }\end{array}$ & Interno & A partir das distribuidoras & $424.090 \mathrm{MWh}$ & 238.017 MWh \\
\hline
\end{tabular}

Fonte: A partir do Relatório de Sustentabilidade Alto Alegre 2011

No ano seguinte, as relações com estes países foram mantidas e a produção cresceu em aproximadamente $0,68 \%$, entretanto, a quantidade destinada ao comércio internacional sofreu aumento de em média $17,43 \%$.

A tendência é cada vez mais aumentar a quantidade de açúcar comercializado externamente, pois devido ao reconhecimento nacional e internacional, faz com que o mercado externo esteja casa vez mais acessível à medida que a demanda mundial aumenta.

No ano seguinte, nota-se também que além do crescimento da produção total, a quantidade de toneladas destinadas ao mercado externo também acompanhou o crescimento da empresa e a demanda mundial. 
Tabela 3. Análise de 2012

\begin{tabular}{|c|c|c|c|c|}
\hline PRODUTO & \multicolumn{2}{|r|}{ MERCADO } & PRODUÇÃO & VENDA \\
\hline \multirow{2}{*}{ Açúcar } & Interno & $\begin{array}{l}\text { São Paulo, Paraná, Santa Catarina e } \\
\text { Rio Grande do Sul }\end{array}$ & \multirow{2}{*}{864.513 ton } & 328.664 ton \\
\hline & Externo & A partir das traders & & 492.506 ton \\
\hline \multirow{2}{*}{ Etanol } & Interno & A partir das distribuidoras & \multirow{2}{*}{$204.116 \mathrm{~m} 3$} & $188.663 \mathrm{~m} 3$ \\
\hline & Externo & A partir das distribuidoras & & Não houve \\
\hline $\begin{array}{l}\text { Energia } \\
\text { elétrica }\end{array}$ & Interno & A partir das concessionárias & $486.571 \mathrm{MWh}$ & 223.301 MWh \\
\hline
\end{tabular}

Fonte: A partir do Relatório de Sustentabilidade Alto Alegre 2012

Considerando que os anos de 2011 e 2012 foram anos de queda nas exportações de açúcar no Brasil, a Usina Alto Alegre manteve-se em crescimento no mercado apesar do seu baixo crescimento durante esses anos. Num período de crise no setor, o crescimento de 1,25\% em relação ao ano anterior torna-se significativamente importante, pois mostra que não foi o suficiente para abalar suas estruturas financeiras e produtivas no período.

As exportações crescem no ritmo acentuado para atender mais países a cada ano; o crescimento de $9,11 \%$ vem deixar claro que as negociações com o restante do mundo não estão estagnadas.

Tabela 4. Análise de 2013

\begin{tabular}{|c|c|c|c|c|}
\hline Produto & & Mercado & Produção & Venda \\
\hline \multirow{2}{*}{ Açúcar } & Interno & São Paulo, Paraná, Santa Catarina e Rio Grande do Sul & \multirow{2}{*}{933.432 ton } & 353.473 ton \\
\hline & Externo & A partir das traders & & 554.258 ton \\
\hline \multirow{2}{*}{ Etanol } & Interno & A partir das distribuidoras & \multirow{2}{*}{$219.842 \mathrm{~m}^{3}$} & $213.268 \mathrm{~m}^{3}$ \\
\hline & Externo & A partir das distribuidoras & & Não houve \\
\hline $\begin{array}{l}\text { Energia } \\
\text { Elétrica }\end{array}$ & Externo & A partir das concessionárias & 463.776 MWh & $258.260 \mathrm{MWh}$ \\
\hline
\end{tabular}

Fonte: A partir do Relatório de Sustentabilidade Alto Alegre 2013.

É possível dizer que entre todos os anos analisados da produção da usina Alto Alegre, 2013 foi o melhor e mais rentável. Devido à volta no crescimento do total exportado pelo Brasil, a referida empresa também apresentou bons resultados em relação à quantidade de açúcar produzido. O crescimento total de 7,92\% e 12,54\% referente às exportações mostra que apesar do consumo interno ser relativamente elevado e também estar em crescimento, o consumo 
internacional cresce em ritmo muito mais acelerado. Pelo fato de diversas usinas encerrarem suas atividades nos últimos anos e a Alto Alegre ser uma renomada e sólida empresa, de certa maneira, favoreceu para que suas atividades fossem intensificadas e ganhasse força diante do mercado devido ao cenário atual.

\section{DISCUSSÃO}

Um fator determinante para o surgimento do agronegócio no Brasil deve-se aos avanços tecnológicos no campo, devido que somente a produção primária já não era suficiente para a comercialização, manutenção e conservação dos produtos, pois de acordo com as necessidades de consumo, determinados alimentos necessitavam de alguns cuidados para que possuíssem uma vida útil mais prolongada.

No Brasil, tais avanços tecnológicos, foram intensificados nos últimos 70 anos e devido a isto, a população que antes residia no campo, passou a migrar para a cidade (ARAUJO, 2010).

As diversas mudanças que ocorreram neste período foram fator determinante para a população tornarem-se cada vez mais urbanas, pois a vida no campo já não atendia a todas as necessidades; iam em busca de insumos e por muitas vezes buscavam uma maior rentabilidade nas cidades, vendendo aquilo que produziam.

De fato, as propriedades passaram a reduzir sua autossuficiência uma vez que agora dependia das tecnologias para produzirem de acordo com a demanda nacional, porém, este histórico foi fundamental para a conquista no mercado nacional e mundial e para o crescimento econômico diante deste segmento; estes que passaram a "agir" de forma interdependente, pois assumiram suas próprias funcionalidades a fim de ser parte integrante do novo complexo agroindustrial que ganhava seu espaço econômico.

Ainda de acordo com o cenário econômico, Callado (2010, p. 66) afirma que "um dos grandes problemas sociais do campo decorre dos efeitos da tendência ao declínio dos preços dos agrícolas, à medida que surgem e são aplicadas novas tecnologias que barateiam os custos de produção".

Uma vez que o agronegócio brasileiro possui papel fundamental para a movimentação da economia, o mesmo também proporciona grandes negociações ao que se diz respeito ao comércio exterior.

Através do surgimento do agronegócio no Brasil, algumas agroindústrias instalaram-se na região de Presidente Prudente e expandiram suas atividades. A região ficou conhecida, desde a sua fundação por ser capaz de abrigar vários produtos e suas respectivas indústrias. 
As atividades agrícolas surgiram na região, a partir da década de 1920, com a cultura do café, que prevaleceu como principal fonte de rentabilidade até meados da década de 1930, onde passou por uma crise, dando espaço ao algodão, até a década de 1940 que segundo Furtado (2000), provocou uma modificação na agricultura tanto no setor interno quanto externo, aumentando a demanda de outros produtos no mercado interno, como arroz, feijão, cana-deaçúcar, milho e outros.

Na visão de Santos e Pessôa (2008, p. 249) “o avanço da cultura da cana-de-açúcar não é um fenômeno isolado, pois vêm acompanhados da valorização das usinas, dos equipamentos e da valorização das terras", estes fenômenos já acorrem desde a década de 1970 quando instalaramse as primeiras usinas no Brasil; desde então houveram incentivos significativos por parte do governo para a intensificação e aumento da produção, uma vez que o interesse no etanol brasileiro crescia por parte dos países estrangeiros devido ao seu baixo custo de produção e isto colaborou para que houvesse maior valorização do setor com o intuito de que todas as propriedades da cana pudessem ser utilizadas.

O cultivo da cana-de-açúcar é recente na região Administrativa de Presidente Prudente, pois somente após a criação do Proálcool e os incentivos do governo, o setor sucroalcooleiro teve oportunidades de consolidação no mercado.

A região é composta por diversas usinas que possuem grande participação no mercado econômico, estando entre elas a Usina Alto Alegre, que é uma das maiores do país. Iniciando suas atividades no estado do Paraná, trouxe para a região, duas unidades que estão em atividade há aproximadamente vinte anos.

Presidente Prudente encontra-se na região Centro-Sul do país, onde é concentrado a maior produção de cana-de-açúcar. De acordo com fontes do Boletim Setor Sucroalcooleiro (online, 2014), mesmo após a crise que atingiu o setor, ocorreram expansões das áreas disponíveis para o cultivo da cana. Isso se deve ao fato que a boa gestão da maior parte das usinas existentes na região, não deixasse que a crise fosse maior que a sua rentabilidade.

Conforme as pesquisas e dados apresentados pelo Ministério da Agricultura - MAPA (online, 2015), o Brasil é responsável por mais da metade do açúcar comercializado no mundo e as projeções para os próximos anos são positivas.

Contudo, vale ressaltar que as práticas industriais na região estão sendo intensificadas num ritmo acelerado e a partir delas surgem melhores condições econômicas para o setor e a contribuição para a economia é mais significativa uma vez que as exportações do setor sucroalcooleiro significam grande parte do PIB brasileiro. 


\section{CONCLUSÃO}

A partir dos dados apresentados, a contribuição do agronegócio para o desenvolvimento da economia foi positiva.

A região de Presidente Prudente é rica na produção e comercialização da cana de açúcar e para conclusão da pesquisa foi utilizado dados da Usina Alto Alegre, que por ser uma importante e conceituada empresa do setor, colabora significativamente para a produção nacional, sendo que além da demanda nacional, atende grandes países com os quais mantém comércio no exterior, que além da comercialização do açúcar, sua produção de etanol e energia elétrica vem crescendo a cada ano, fazendo com que o reconhecimento da empresa seja cada vez mais significativo no mercado.

Portanto, se não fosse a contribuição do agronegócio para a economia e a grande produção e exportação de açúcar, a situação econômica brasileira estaria numa situação ainda mais crítica da qual se encontra atualmente.

\section{REFERENCIAS}

ARAUJO, M. J. Fundamentos de Agronegócios. 3 ed. São Paulo: Atlas, 2010.

CALLADO, A. A. C. Agronegócio. 3 ed. São Paulo: Atlas, 2011.

FURTADO, M. B. Síntese da economia brasileira. 7 ed. Rio de Janeiro: LTC, 2000.

Ministério da Agricultura. Cana-de-açúcar. Disponível em: < http://www.agricultura.gov.br/vegetal/culturas/cana-de-acucar>. Acesso em: 04 Mai. 2015.

NAKABASHI, Luciano; CONDI, Juliano. Boletim Setor Sucroalcooleiro. Disponível em: <https://drive.google.com/file/d/OB5Pu-CHNX3_BTm9SdGhwMVFldGc/view?pli=1> Acesso em: 07 Mar. 2015.

SANTOS, J. C.; PESSÔA, V. L. S. A territorialização das empresas do setor sucroalcooleiro na microrregião geográfica de Presidente Prudente - SP: As tramas do capital e os impactos no mundo do trabalho. Disponível em: <http://www.seer.ufu.br/index.php/campoterritorio/article/viewFile/11847/6934>. Acesso em: 01 Fev. 2015.

USINA ALTO ALEGRE. Relatório de Sustentabilidade. Disponível em: <http://www.altoalegre.com.br/docs/RELATORIO_SUSTENTABILIDADE_2010.pdf>. Acesso em 02 Fev. 2015.

USINA ALTO ALEGRE. Relatório de Sustentabilidade. Disponível em: <http://www.altoalegre.com.br/docs/RELATORIO_SUSTENTABILIDADE_2011.pdf>. Acesso em 02 Fev. 2015. 
USINA ALTO ALEGRE. Relatório de Sustentabilidade. Disponível em: <http://www.altoalegre.com.br/docs/RELATORIO_SUSTENTABILIDADE_2012.pdf>. Acesso em 02 Fev. 2015.

USINA ALTO ALEGRE. Relatório de Sustentabilidade. Disponível em: <http://www.altoalegre.com.br/docs/RELATORIO_SUSTENTABILIDADE_2013.pdf>. Acesso em 02 Fev. 2015. 